\title{
PF/CLAY hybrid materials: a simple method to modulate the optical properties
}

\author{
Marcio Chao Chen Em¹, Camila Gouveia Barbosa', Laura Oliveira Péres ${ }^{1 *}$ and Roselena Faez² \\ ${ }^{1}$ Laboratory of Hybrid Materials, Institute of Environmental, Chemical and Pharmaceutical Sciences, \\ Universidade Federal de São Paulo - UNIFESP, Diadema, SP, Brazil \\ ${ }^{2}$ Laboratory of Polymeric and Biosorbent Materials, Department of Natural Science, \\ Mathematics and Education, Universidade Federal de São Carlos - UFSCar, Araras, SP, Brazil
}

\author{
*lauraoperes@gmail.com
}

\begin{abstract}
The aim of this work was modulate the emission properties and improve thermal stability of a conjugated polymer incorporated into an inorganic matrix. Hybrid material was prepared based on poly(9,9-dioctylfluorene-co-phenylene (PF) and montmorillonite $\left(\mathrm{Na}^{+} \mathrm{Mt}\right.$ ) clay using wet impregnation of 10,30 and 50 wt.\% of $\mathrm{PF}$ into $\mathrm{Na}^{+} \mathrm{Mt}$ and $\mathrm{Na}{ }^{+} \mathrm{Mt}$ intercalated with ammonium quaternary salts (hexadecyltrimethylammonium — HDTMA) in a different proportions (OMt-1 and OMt-2). The materials were characterized by infrared and UV-Vis spectroscopy, fluorescence, X-ray diffratometry and thermogravimetry analysis. The results show that the presence of the clay alters the photoluminescent and thermal properties. Nevertheless, the degree of the clay organophilization and the clay content influences the luminescent properties due to the diverse interaction behavior between the polymer and clay. The sodium clay acted only as dispersing agent since no intercalation process occurs and the emission displacement is assigned to this behavior. In this case the PF emission displace from 402 to $395 \mathrm{~nm}$. A nonlinear displacement is observed for PF/OMt- 2 due the difficulties to conclude if the intercalation of the polymer occurs $(379,403$ and 412 for hybrid with 10, 30 and $50 \%$, respectively). For PF/OMt-1 a higher displacements for lower wavelength is observed due to intercalation of polymer chains and subsequent isolation in the interlamellar space, especially with material with 10 and $30 \%$ of PF in the hybrid material, whose displacement reached to $360 \mathrm{~nm}$. All these results show that is possible to try to control the emission of the conjugated hybrid material changing the rate of the material.
\end{abstract}

Keywords: polyfluorene, clay, hybrid materials, photoluminescence.

\section{Introduction}

Among the luminescent conjugated polymers polyfluorene (PF) family, PF is one of the most used and developed due to its high chemical and thermal stabilities. This behavior reflects the spectral stability allowing the formation of liquid-crystalline phase and thus supports the manufacture of electroluminescent device with highly polarized light emission $^{[1]}$. PF have high efficiency in the blue region and can be prepared as copolymers with others light emitting polymers ${ }^{[2]}$. Furthermore, it can be modulated to emit in the visible region ranging from blue to red ${ }^{[3,4]}$. This can occur when substituents are inserted in the polymer chain and affect the properties such as, solubility, thermal stability, conductivity, optical and electrochemical properties ${ }^{[3,5,6]}$. Also, materials can be obtained with high photoluminescence quantum efficiency and good quantum transport charges ${ }^{[5,7-9]}$.

Hybrid inorganic/organic materials have been extensively studied mainly because of their intrinsic properties obtained by a synergistic effect of its components ${ }^{[10-17]}$. The combination of conjugated polymers and inorganic matrix such as layered silicates, ordered mesoporous silica and carbon nanotubes have great interest because of the potential applications in electrical and electronic sectors ${ }^{[18-21]}$. Among the layered silicates class the mineral clays presents important characteristics, besides of that the naturally occurring materials, such cation exchange capacity, high surface area and capacity for adsorption/absorption properties ${ }^{[16,22-25]}$.

It is also well known to the scientific community that the synergistic combination of these materials that improve the photoluminescence quantum efficiency ${ }^{[26-30]}$. Further the presence of inorganic phase can also modify the color of emission $^{[31]}$. The displacement of the emission peak may be associated to the decrease of the polymer aggregation process which the optical properties of conjugated polymers are dependent of chain conformation. It is known that the isolation of conjugated polymer chains within inorganic materials plays an important role in improving the luminescent efficiency and controlling interchain transfer energy ${ }^{[31,32]}$.

Different methodologies can be used to combine the polymer and inorganic host. The polymer chain can be inserted by intercalation when the inorganic matrix has lamellar structure such as natural aluminosilicates. These nanohybrids of polymer/clay have an improved properties when compared with their analogues pure polymers, such as thermal and mechanical stability, chemical resistance and performance against photodegradation ${ }^{[27,33]}$.

In this context, we report the preparation of montmorilonite and PF hybrids materials and their structural (FTIR and $\mathrm{XRD}$ ), thermal (TG) and luminescence characterization. 
The drive for the use of lamellar structure as montmorillonite clay was related to its good thermal and chemical stability and the possibility to isolate the polymer chain.

\section{Experimental Section}

\subsection{Polymer synthesis}

Poly(9,9-dioctylfluorene)-co-phenylene ( $\mathrm{PF})$ was synthesized as describe in the literature ${ }^{[32,33]}$ using 9,9-dioctylfluorene2,7-dibromofluorene, 1,4-phenylenebisboronic acid and tetrakis-(triphenylphosphine) palladium $\left(\mathrm{P}\left(\mathrm{Ph}_{3}\right)_{4} \mathrm{Pd}\right)$ as a catalyst.

\subsection{Organophilization of montmorilonitte}

Sodium montmorillonite clay, $\left(\mathrm{Na}^{+} \mathrm{Mt}\right)$ (Bentonit União Nordeste, Brazil) with a cation exchange capacity (CEC) of $85 \mathrm{meq} / 100 \mathrm{~g}$ of clay was organophilized with hexadecyltrimethylammonium bromide (HDTMAB, Aldrich) according to the Fontana et al. ${ }^{[34]}$ The mineral clay was dispersed in an aqueous HDTMA solution using weight ratios (HDTMA:Na+Mt) of 1:1 and 1:2 based on the CEC of the clay. The organomodified clays (OMt) were respectively named as OMt-1.0 and OMt -2.0 .

\subsection{Preparation of PF/clay}

In a Erlenmeyer, equipped with a magnetic stirring, $0.5 \mathrm{~g}$ of the clays were first dispersed in $18 \mathrm{~mL}$ of ethanol $(\mathrm{Na}+\mathrm{Mt})$ and toluene (OMt-1 and OMt-2) and $0.05 \mathrm{~g}$ of PF (for 10\% in mass of polymer) was dissolved in toluene. After complete dispersion the solutions were mixed and kept closed under magnetic stirring for 48 hours. Subsequently, the solvent was removed and the material was dried. PF-clay hybrids were prepared with 10,30 and $50 \%$ in mass of polymer and respectively named as $\mathrm{Na}^{+} \mathrm{Mt} / \mathrm{PF}(10), \mathrm{Na}^{+} \mathrm{Mt} / \mathrm{PF}(30)$, $\mathrm{Na}^{+} \mathrm{Mt} / \mathrm{PF}(50), \mathrm{OMt}-1 / \mathrm{PF}(10), \mathrm{OMt}-1 / \mathrm{PF}(30), \mathrm{OMt}-1 / \mathrm{PF}(50)$, OMt-2/PF(10), OMt-2/PF(30) and OMt-2/PF(50).

\subsection{Characterization}

UV absorption spectra were collected on a Varian Cary 50 spectrophotometer. The materials were dispersed in spectroscopic chloroform $\left(1 \times 10^{-5} \mathrm{~mol} / \mathrm{L}\right)$, with the solution being poured into a $10 \mathrm{~mm}$ square quartz cell. The absorption spectrum was collected in the range $\lambda=200-600 \mathrm{~nm}$. Photoluminescence (PL) spectra were taken with a Varian Eclipse fluorescence spectrophotometer. Powder sample was pressed into two plates of glass and excited at $315 \mathrm{~nm}$. The spectra of the solution were performed in spectroscopic chloroform $\left(1 \times 10^{-5} \mathrm{~mol} / \mathrm{L}\right)$, with excitation at the wavelength of the maximum absorption according to the UV-Vis spectra. TG curves were obtained in a thermogravimetric analyzer TG-60/60 $\mathrm{H}$ (Shimadzu) from $50{ }^{\circ} \mathrm{C}$ to $900{ }^{\circ} \mathrm{C}$ at a heating rate of $10{ }^{\circ} \mathrm{C} \cdot \mathrm{min}^{-1}$ under nitrogen atmosphere ( $200 \mathrm{~mL} / \mathrm{min}$ ), sample weight $10 \mathrm{mg}$. Infrared spectra were recorded in the range $4000-400 \mathrm{~cm}^{-1}$ in $\mathrm{KBr}$ pellets, using a BOMEM MB-100 spectrometer. $X$ ray diffraction (XRD) patterns of powdered samples were recorded on a Rigaku diffractometer model Miniflex using $\mathrm{Cu}-\mathrm{K} \alpha$ radiation $(1.541 \AA, 30 \mathrm{kV}$ and $15 \mathrm{~mA})$.

\section{Results and Discussion}

As previous pointed out, $\mathrm{PF} / \mathrm{Na}^{+} \mathrm{Mt}$ and $\mathrm{PF} / \mathrm{OMt}$ composites were prepared by dispersing PF and both clays in a solvent. After that solid materials were separated, dried and used for structural (FTIR and XRD), thermal (thermogravimetry) and absorption-emission (UV-Vis and photoluminescence) characterization.

FTIR spectra of PF and its hybrids prepared with $50 \mathrm{wt} . \%$ are shown in Figure 1, and the Table 1 summarizes the main bands and their assignments. The characteristic bands of the polyfluorene are verified mainly at $1599 \mathrm{~cm}^{-1}$ to $\mathrm{C}=\mathrm{C}$ stretching vibrations, $1460 \mathrm{~cm}^{-1}$ to $\mathrm{CH}_{2}$ bending of fluorine group and 812 and $760 \mathrm{~cm}^{-1}$ assigned to $\mathrm{C}-\mathrm{H}$ stretching vibrations. The bands of boronic group (1320 and $\left.1350 \mathrm{~cm}^{-1}\right)$, presented in the started materials, cannot be shown, indicating the formation of the polymer. In the hybrids it is possible to observe the silicate related absorption bands at $1030 \mathrm{~cm}^{-1}$ for Si-O-Si stretching and 528 and $470 \mathrm{~cm}^{-1}$ for Si-O stretching and bending, respectively. The presence of the bands at 2925 and $2854 \mathrm{~cm}^{-1}$ (aliphatic CH stretching) arising PF and clay can be seen. But, the presence of the PF, in the hybrid, can be confirmed through the bands at $1599 \mathrm{~cm}^{-1}$ (aromatic ring stretching) and $1300 \mathrm{~cm}^{-1}(\mathrm{CH}$

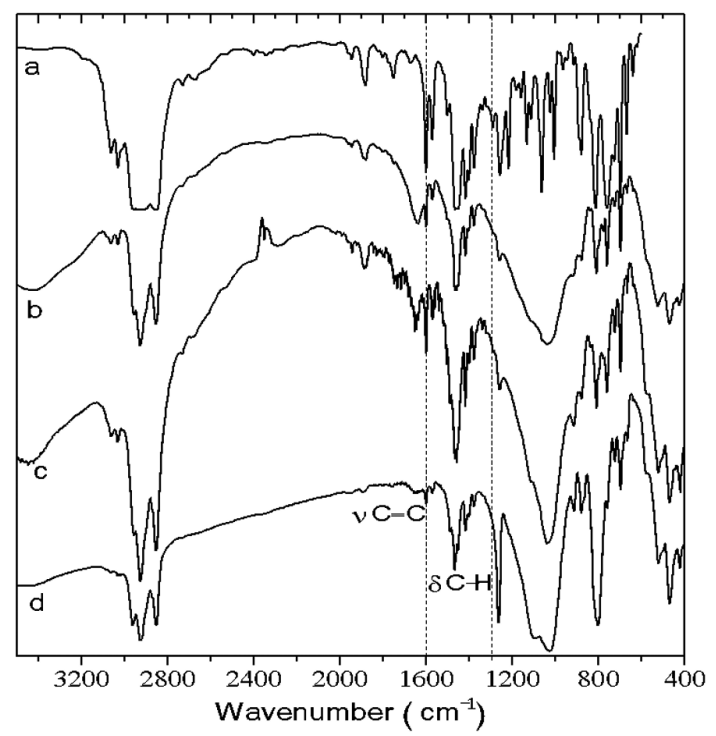

Figure 1. FTIR spectra of (a) PF and hybrids prepared with 50 wt.\% of (b) $\mathrm{Na}^{+} \mathrm{Mt}$; (c) OMt-1 and (d) OMt-2.

Table 1. Position and respective assignment of the main bands present at the FTIR spectra of PF and hybrids materials.

\begin{tabular}{cc}
\hline $\begin{array}{c}\text { Band Position } \\
\text { (wavenumber } \mathbf{~ m}^{-1} \text { ) }\end{array}$ & Assignment \\
\hline 528 and 470 & Si-O stretching and bending \\
812 and 760 & $\mathrm{C}-\mathrm{H}$ stretching vibrations \\
1030 & Si-O-Si stretching \\
1300 & $\mathrm{CH}$ in-plane deformation \\
1460 & $\mathrm{CH}_{2}$ bending of fluorine group \\
1599 & $\mathrm{C}=\mathrm{C}$ stretching vibrations \\
2925 and 2854 & aliphatic $\mathrm{CH}$ stretching \\
\hline
\end{tabular}


in-plane deformation), as can be seen in the dash line in the graph. Throughout the spectral region no displacement and/ or appearance of new bands are observed in the composites suggesting no chemical interaction between the components. Similar results were observed for other proportions.

XRD difractograms of clays and its hybrids in a proportion of 50 wt. \% are shown in Figure 2. The organomodification of the $\mathrm{Na}^{+} \mathrm{Mt}$ with $\mathrm{HDTMA}^{+}$was successfully realized. The interlayer space was increased as $\mathrm{HDTMA}^{+}$was inserted in the basal area as observed by an increase in interlayer

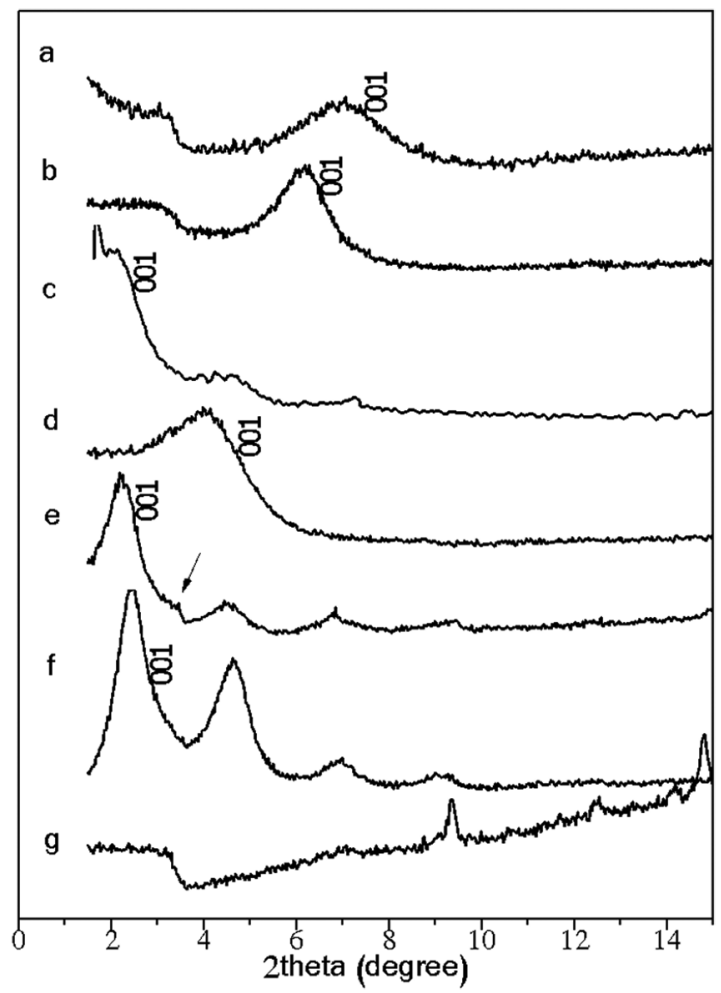

Figure 2. X-ray diffraction patterns of (a) $\mathrm{PF} / \mathrm{Na}+\mathrm{Mt}$; (b) $\mathrm{Na}+\mathrm{Mt}$; (c) PF/OMt-1; (d) OMt-1; (e) PF/OMt-2; (f) OMt-2 and (g) PF.



space from 1.4 to 2.2 and $3.6 \mathrm{~nm}$ for $\mathrm{Na}^{+} \mathrm{Mt}$ to OMt- 1 and OMt-2, respectively ${ }^{[34,35]}$. Figure 2 also compare the XRD patterns of the clays with its hybrids. From $\mathrm{Na}^{+} \mathrm{Mt}$ and $\mathrm{Na}^{+} \mathrm{Mt} / \mathrm{PF}(50)$ no changes in the basal spacing is observed suggesting the $\mathrm{Na}^{+} \mathrm{Mt}$ only acted as a dispersed phase to dilute and de-aggregate the polymer chains. Comparing OMt-1 and OMt-1/PF(50) it is observed a decrease on the peak associate with basal plane $d_{001}$ increasing the interlayer space from 2.18 to $4.20 \mathrm{~nm}$. These results strongly suggest the intercalation of the polymer chain and also corroborated to the emission spectra of the hybrids, as discussed later.

For OMt-2/PF(50) a small dislocations in the $d_{001}$ of OMt-2 is observed. However, it is observed the appearance of new peak at $2 \theta$ equal $3.4^{\circ}$. The $d_{001}$ peak dislocation and the formation of a new phase (arrow in the Figure 2f) could suggest the presence of the polyfluorene in the clay.

Thermal behavior of PF, clay and hybrids was evaluated by thermogravimetry analysis in nitrogen atmosphere and Figure 3 show the TG and DTG curves. For PF only one stage of weight loss is observed $\left(\mathrm{Ti}=284^{\circ} \mathrm{C}\right)$ addressed to the main chain degradation ${ }^{[36]}$. The $\mathrm{PF} / \mathrm{Na}^{+} \mathrm{Mt}(50)$ present two stage of thermodecomposition. The first one assigned to the water loss and the second one (from 230 to $410^{\circ} \mathrm{C}$ ) to the PF degradation (50\% of weigh loss). PF/OMt-1(50) and PF/OMt-2(50) shows three stage of weight loss. The first one assigned mainly to the quaternary ammonium ion degradation and the second and third stages, from 220 to $450^{\circ} \mathrm{C}$, due to the ammonium ion and $\mathrm{PF}$ degradation. The DTG curves show better the event separation, Figure 4. However, for higher amount of quaternary salt lower the initial temperature of degradation since the ammonium salt has lower stability. For others compositions the results are similar (not shown here).

Figure 4 shows the absorption and emission curves in chloroform solution of $\mathrm{PF}$ and hybrids prepared with $\mathrm{Na}^{+} \mathrm{Mt}$, OMt-1 and OMt-2. It is not observed displacement and/or appearance of new bands on hybrids spectra compared to the bulk polymer. It is possible to realize that, the excitation of the electrons from the valence band to the conduction band, ie, the beginning of the $\pi-\pi^{*}$ transition, occurs at $350 \mathrm{~nm}(3.5 \mathrm{eV})$. This band gap energy, corresponding to the traditional band gap range of semiconductor materials,

Figure 3. TG and DTG curves of (a) pure PF and PF with 50 wt.\% of (b) Na+Mt; (c) OMt-1 and (d) OMt-2.

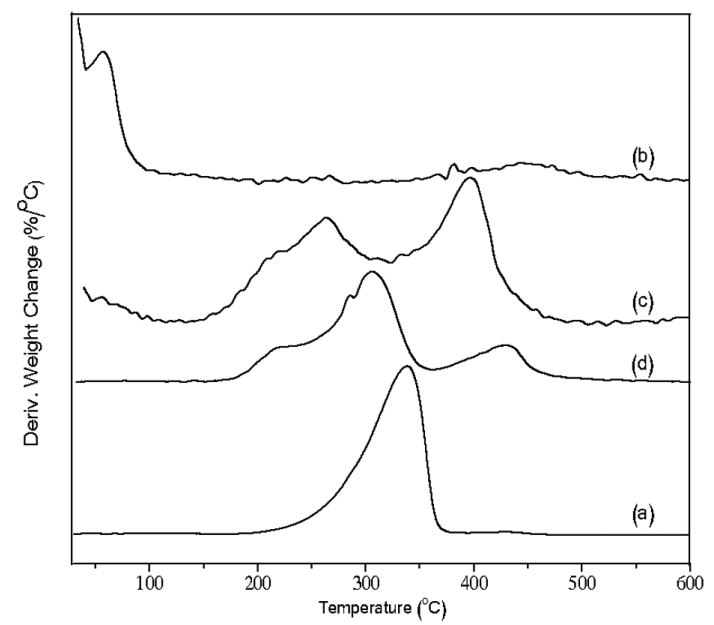


shows the conductive properties of this polymer. In the emission spectra the maxima are found at 360 and $377 \mathrm{~nm}$. For hybrids there is an inversion of the bands intensities

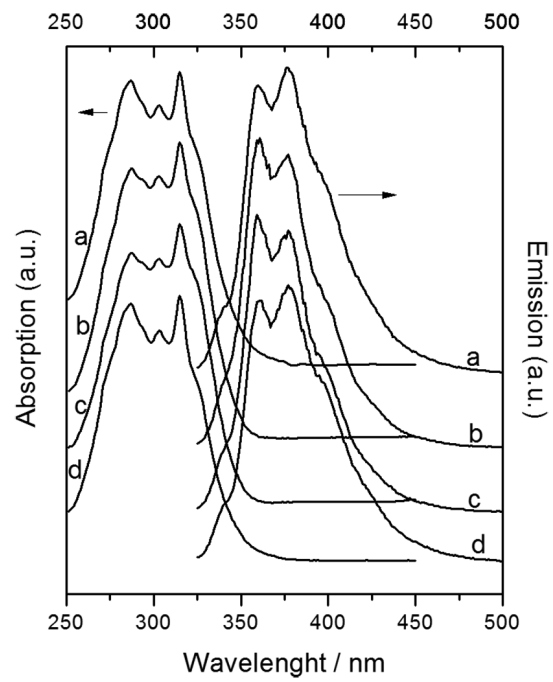

Figure 4. Absorption and emission spectra in chloroform of (a) pure $\mathrm{PF}$ and hybrids of $\mathrm{PF}$ prepared with $50 \mathrm{wt} . \%$ of (b) $\mathrm{Na}+\mathrm{Mt}$; (c) OMt-1 and (d) OMt-2.
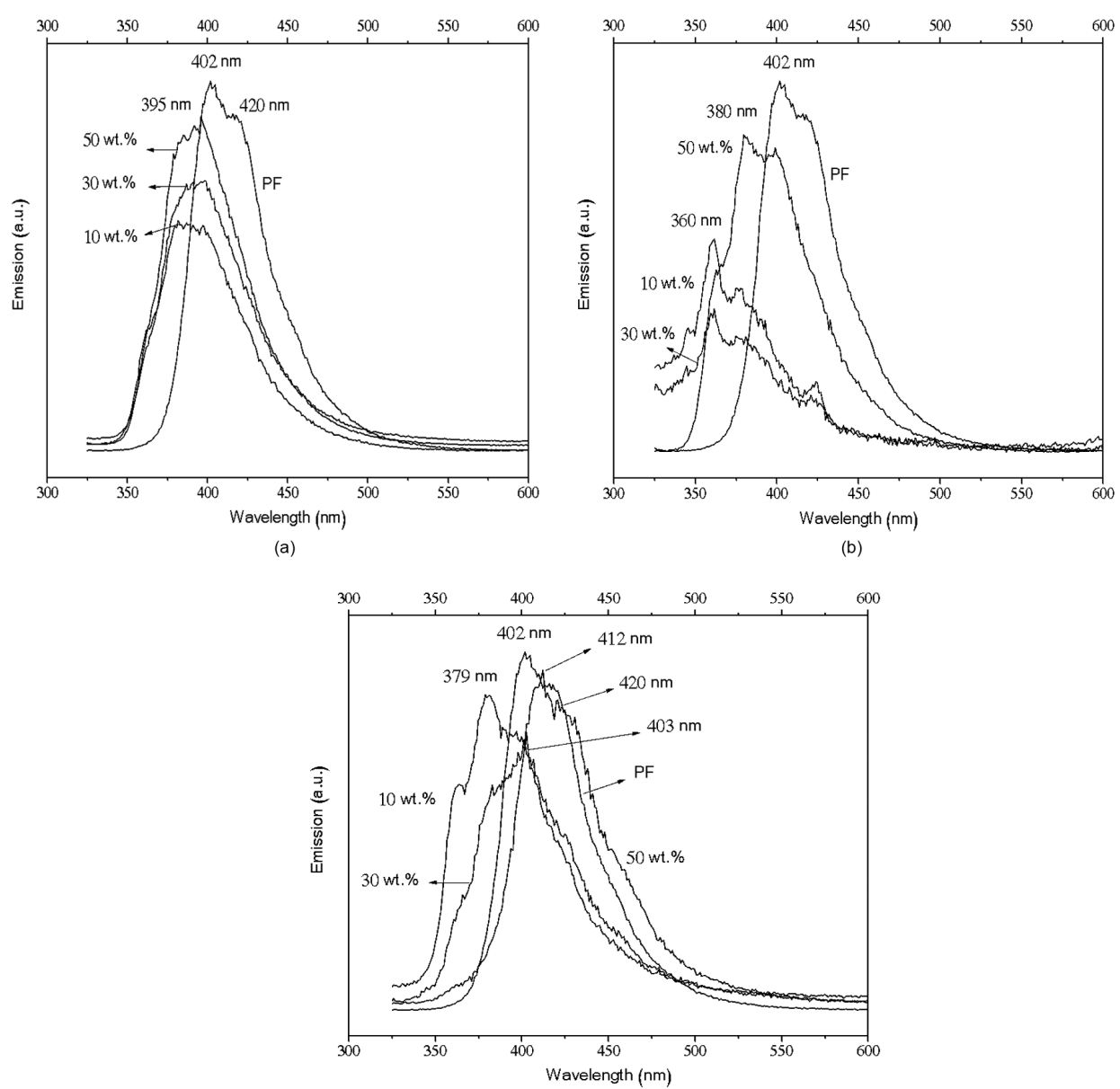

(c)

Figure 5. Solid state spectra of pure PF and hybrids of PF with (a) $\mathrm{Na}^{+} \mathrm{Mt}$; (b) OMt-1 and (c) OMt-2. compared to the pure polymer. This behavior may be related to the vibronic structure which is associated to the $\mathrm{C}=\mathrm{C}$ stretching mode band (at $1599 \mathrm{~cm}^{-1}$ in the infrared spectrum $)^{[37]}$. Normally, the absorption and emission spectra are specular. This symmetry is due to the transitions involved, i.e., for emission spectra the transition occurs of an excited state $n$ to the fundamental and for absorption spectra the process is reversed. In real polymer systems is difficult to separate those different processes due to the widths of bands and thus the specularity normally is not observed. Usually the spectra are broad due to interchain processes associated with the effects of homogeneity of the film, conformational disorder and multiple processes of decays. Moreover, the energy transition $\pi-\pi^{*}$ depends on the conjugation length, the distribution of absorption energy expansion and the vibronic structure of a particular segment. Instead, the emission spectra exploiting only sites of lower energy. Accordingly, two possibilities can explain the obtained results in solution, that is, no displacement to the pure polymer; the portion of polymer adsorbed on the clays surface, out of the lamellae, have the main contribution to the emission of the material, or the lability makes the polymer comes out of the lamellae. The same behaviors are observed for others hybrids.

Figure 5 shows the solid state emission spectra for PF and hybrid materials. A shift of the maximum peak for solid 
spectrum of PF was verified compared the one obtained in solution (from 377 to $402 \mathrm{~nm}$ ). For Na+Mt/PF, Figure 5a, a single broadband at $395 \mathrm{~nm}$ is observed regardless the amount of PF and a blue shift from 402 to $395 \mathrm{~nm}$ is verified. This result is in agreement with the XDR suggesting the polymer is not into the clay, but this can act as a dispersed phase to dilute the polymer chain. For OMt-1/PF, Figure 5b, there is also a blue shift of the maximum peak. However, the amount of polymer affects the band displacement. For OMt-1/PF(50) a displacement from 402 to $380 \mathrm{~nm}$ was observed whereas for OMt-1/PF(10) and OMt-1/PF(30) a shift from 402 to $360 \mathrm{~nm}$. For hybrids prepared OMt-2 the change in the spectra compare to PF was even greater. Initially no linearity in the behavior was observed or just blue shift when clay was added. Rationalizing and analyzing only the hybrids a red shift is detected increasing the polyfluorene and a maximum at 379,403 and $412 \mathrm{~nm}$ for the hybrids with 10,30 and $50 \mathrm{wt} . \%$, respectively is found.

The above results can be explained based on the aggregation and de-aggregation phenomenon. According to Scherf and List $^{[38]}$, the agglomeration process of the particles shifts the emission spectrum to longer wavelengths (red). This behavior is observed in the solution and solid state spectra of bulk polyfluorene. As a consequence, as more isolated species the higher is the frequency observed ${ }^{[39]}$. More isolated species (more de-aggregated) are found for hybrids prepared with OMt- 1 at low percentage (10 and $30 \mathrm{wt} . \%)$. In fact, the process of isolation-association (aggregation-de-aggregation) is not the only phenomenon observed in the hybrids. An important statement is related to the folding process of the polymer and the mechanism of polymer intercalation in the clays. Ramachandran et al. ${ }^{[28]}$ suggests that the material can be fully, partially or non-intercalated. The larger the quantity of material is sandwiched within the lamellae, the higher the red shift, due to the higher amount of aggregated material. Moreover, when the polymer chains are interspersed, the effective conjugation length increases due to the planarization of the chain. In this case the transfer of the Förster energy is difficult and, instead, the intrachain energy transfer can become dominant. Therefore, the higher-energy excitons migrate to the lowest energy state along the chain, resulting in a red shift of the spectrum ${ }^{[10]}$. The intercalation process can also provide an additional environment to change the emission color by changing the effective conjugation length. Finally, for OMt2/PF(50), three factors influence the observed shift: (i) larger intercalation of polymeric material, (ii) increase of the chains association, (iii) increase the intrachain energy transfer. $10 \mathrm{wt} . \%$.

\section{Conclusions}

Through simple technique, via wet impregnation, was possible to prepare luminescent materials consisting of polyfluorene and montmorillonite clay. Modulated emission values were obtained depending on the clay modification and the amount of polymeric material. The results suggest no chemical interaction between the components, but the X-ray diffraction strongly suggests the intercalation of the polymer chain and also corroborated to the emission spectra of the hybrids. Based on the results we can indicate this composite to be used as active material in an optoelectronic devices.

\section{Acknowledgements}

The authors thank FAPESP (07/50742-2), CNPq, Capes-nBioNet and INEO-INCT (National Institute of Science and Technology for Organic Electronics) for financial support. The authors also thank Prof. Dr. Marcos Augusto Bizeto and Prof. Dr. Tereza da Silva Martins for DRX analysis.

\section{References}

1. Bernius, M. T., Inbasekaran, M., O’Brien, J., \& Wu, W. S. (2000). Progress with light-emitting polymers. Advanced Materials, 12(23), 1737-1750. http://dx.doi.org/10.1002/15214095(200012)12:23<1737::AID-ADMA1737>3.0.CO;2-N.

2. Cirpan, A., Ding, L., \& Karasz, F. E. (2005). Optical and electroluminescent properties of polyfluorene copolymers and their blends. Polymer, 46(3), 811-817. http://dx.doi. org/10.1016/j.polymer.2004.11.107.

3. Akcelrud, L. (2003). Electroluminescent polymers. Progress in Polymer Science, 28(6), 875-962. http://dx.doi.org/10.1016/ S0079-6700(02)00140-5.

4. List, E. J. W., Guentner, R., Scanducci de Freitas, P., \& Scherf, U. (2002). The effect of keto defect sites on the emission properties of polyfluorene-type materials. Advanced Materials, 14(5), 374-378. http://dx.doi.org/10.1002/15214095(20020304)14:5<374::AID-ADMA374>3.0.CO;2-U.

5. Oliveira, H. P. M., Cossiello, R. F., Atvars, T. D. Z., \& Akcelrud, L. (2006). Dispositivos poliméricos eletroluminescentes. Quimica Nova, 29(2), 277-286. http://dx.doi.org/10.1590/ S0100-40422006000200019.

6. Kaya, I., Yıldırım, M., Aydın, A., \& Senol, D. (2010). Synthesis and characterization of fluorescent graft fluorene-co-polyphenol derivatives: the effect of substituent on solubility, thermal stability, conductivity, optical and electrochemical properties. Reactive \& Functional Polymers, 70(10), 815-826. http:// dx.doi.org/10.1016/j.reactfunctpolym.2010.07.013.

7. Shakutsui, M., Matsuura, H., \& Fujita, K. (2009). Improved efficiency of polymer light-emitting diodes by inserting a hole transport layer formed without thermal treatment above glass transition temperature. Organic Electronics, 10(5), 834-842. http://dx.doi.org/10.1016/j.orgel.2009.04.004.

8. Stéphan, O., Collomb, V., Vial, J.-C., \& Armand, M. (2000). Blue-green light-emitting diodes and electrochemical cells based on a copolymer derived from fluorine. Synthetic Metals, 113(3), 257-262. http://dx.doi.org/10.1016/S0379-6779(00)00214-9.

9. Zhao, W., Cao, T., \& White, J. M. (2004). On the origin of green emission in polyfluorene polymers: the roles of thermal oxidation degradation and crosslinking. Advanced Functional Materials, 14(8), 783-790. http://dx.doi.org/10.1002/adfm.200305173.

10. Lee, T.-W., Park, O. O., Kim, J.-J., Hong, J.-M., \& Kim, Y. C. (2001). Efficient photoluminescence and electroluminescence from environmentally stable polymer/clay nanocomposites. Chemistry of Materials, 13(6), 2217-2222. http://dx.doi. org/10.1021/cm010201h.

11. Barbosa, R., Araújo, E. M., Oliveira, A. D., \& Melo, T. J. A. (2006). Efeito de sais quaternários de amônio na organofilização de uma argila bentonita nacional. Cerâmica, 52(324), 264-268. http://dx.doi.org/10.1590/S0366-69132006000400009.

12. Colvin, V. L., Schlamp, M. C., \& Alivisatos, A. P. (1994). Lightemitting diodes made from cadmium selenide nanocrystals and a semiconducting polymer. Nature, 370(6488), 354-357. http://dx.doi.org/10.1038/370354a0.

13. Hagrman, P. J., Hagrman, D., \& Zubieta, J. (1999). Organic inorganic hybrid materials: from "simple" coordination polymers to organodiamine-templated molybdenum oxides. Angewandte 
Chemie International Edition, 38(18), 2638-2684. http://dx.doi org/10.1002/(SICI)1521-3773(19990917)38:18<2638::AIDANIE2638>3.0.CO;2-4. PMid:10508356.

14. Santos, M. A., Mattoso, L. H. C., Defácio, R., \& Jamshid, A. (2001). Compósitos de borracha natural com compostos condutivos à base de negro de fumo e polímero condutor. Polimeros: Ciência e Tecnologia, 11(3), 126-134. http://dx.doi. org/10.1590/S0104-14282001000300012.

15. Kim, J., Kim, B., Anand, C., Mano, A., Zaidi, J. S. M., Ariga, K., You, J., Vinu, A., \& Kim, E. (2015). A single-step synthesis of electroactive mesoporous ProDOT-silica structures. Angewandte Chemie International Edition, 54(29), 8407-8410. http://dx.doi. org/10.1002/anie.201502498. PMid:26037244.

16. Nakao, A., \& Fujiki, M. (2015). Visualizing spontaneous physisorption of non-charged $\pi$-conjugated polymers onto neutral surfaces of spherical silica in nonpolar solvents. Polymer Journal, 47(6), 434-442. http://dx.doi.org/10.1038/ pj.2015.14.

17. Joshi, P. B., \& Zhang, P. (2015). Facile capture of conjugated polymer nanodots in silica nanoparticles to facilitate surface modification. Journal of Materials Science, 50(10), 3597-3603. http://dx.doi.org/10.1007/s10853-015-8920-5.

18. Paiva, L. B., Morales, A. R., \& Díaz, F. R. V. (2008). Argilas organofílicas: características, metodologias de preparação, compostos de intercalação e técnicas de caracterização. Cerâmica, 54(330), 213-226. http://dx.doi.org/10.1590/S036669132008000200012.

19. De Barros, A., Ferreira, M., Constantino, C. J. L., \& Ferreira, M. (2014). Nanocomposites based on LbL films of polyaniline and sodium montmorillonite clay. Synthetic Metals, 197, 119125. http://dx.doi.org/10.1016/j.synthmet.2014.09.001.

20. Fatnassi, M., \& Es-Souni, M. (2015). Nanoscale phase separation in laponite-polypyrrole nanocomposites. Application to electrodes for energy storage. Royal Society of Chemistry, 5(28), 21550-21557. http://dx.doi.org/10.1039/C4RA16540C.

21. Feng, L., Sha, J., He, Y., Chen, S., Liu, B., Zhang, H., \& Lü, C. (2015). Conjugated polymer and spirolactam rhodamine-B derivative co-functionalized mesoporous silica nanoparticles as the scaffold for the FRET-based ratiometric sensing of mercury (II) ions. Microporous and Mesoporous Materials, 208, 113119. http://dx.doi.org/10.1016/j.micromeso.2015.01.039.

22. Silva, A. A., Valenzuela-Diaz, F. R., Martins, G. S. V., \& Rodrigues, M. G. F. (2007). Preparation of organophilic clays using different concentrations of quaternary ammonium salt. Cerâmica, 53(328), 417-422. http://dx.doi.org/10.1590/S036669132007000400013

23. Park, J. H., Lim, Y. T., Park, O. O., Yu, J.-W., Kim, J. K., \& Kim, Y. C. (2004). Enhanced quantum efficiency in blue-emitting polymer/dielectric nanolayers nanocomposite light-emitting devices. Materials Science and Engineering C, 24(1-2), 75-78. http://dx.doi.org/10.1016/j.msec.2003.09.039.

24. Zheng, M., Ding, L., Lin, Z., \& Karasz, F. E. (2002). Synthesis and Characterization of Fluorenediylvinylene and Thiophenediylvinylene-Containing Terphenylene-Based Copolymers. Macromolecules, 35(27), 9939-9946. http:// dx.doi.org/10.1021/ma020533n.

25. Ramôa, S. D. A., Merlini, C., Barra, G. M. O., \& Soares, B. G. (2014). Obtenção de nanocompósitos condutores de montmorilonita/polipirrol: Efeito da incorporação do surfactante na estrutura e propriedades. Polímeros: Ciência e Tecnologia, 24(ESP), 57-62. http://dx.doi.org/10.4322/polimeros.2014.051.

26. Lee, T. W., Park, O. O., Yoon, J., \& Kim, J. (2001). Enhanced quantum efficiency in polymer/layered silicate nanocomposite light emitting devices. Synthetic Metals, 121(1), 1737-1738. http://dx.doi.org/10.1016/S0379-6779(00)01493-4.
27. Jing, C., Chen, L., Shi, Y., \& Jin, X. (2005). Synthesis and characterization of exfoliated MEHPPV/clay nanocomposites by in situ polymerization. European Polymer Journal, 41(10), 2388-2394. http://dx.doi.org/10.1016/j.eurpolymj.2005.05.007.

28. Ramachandran, G., Simon, G. P., Cheng, Y. B., \& Dai, L. (2005). Control of fluorescence emission color of benzo 15-crown-5 ether substituted oligo phenylene vinylene-ceramic nanocomposites. Polymer, 46(18), 7176-7184. http://dx.doi. org/10.1016/j.polymer.2005.05.087.

29. Evans, R. C., Macedo, A. G., Pradhan, S., Scherf, U., Carlos, L. D., \& Burrows, H. D. (2010). Fluorene based conjugated polyelectrolyte/silica nanocomposites: chatge-mediated phase aggregation at the organic-inorganic interfece. Advanced Materials, 22(28), 3032-3037. http://dx.doi.org/10.1002/ adma.200904377. PMid:20535734.

30. Winkler, B., Dai, L., \& Mau, A. W.-H. (1999). Organicinorganic hybrid light-emitting composites: poly(p-phenylene vinylene) intercalated clay nanoparticles. Journal of Materials Science Letters, 18(19), 1539-1541. http://dx.doi. org/10.1023/A:1006610926414.

31. Lee, H.-C., Lee, T.-W., Lim, Y. T., \& Park, O. O. (2002). Improved environmental stability in poly(p-phenylene vinylene)/ layered silicate nanocomposite. Applied Clay Science, 21(5-6), 287-293. http://dx.doi.org/10.1016/S0169-1317(02)00090-X.

32. Santos, T. C. F., Peres, L. O., Wang, S. H., Oliveira, O. N. Jr, \& Caseli, L. (2010). Mixing alternating copolymers containing fluorenyl groups with phospholipids to obtain Langmuir and Langmuir-Blodgett films. Langmuir, 26(8), 5869-5875. http:// dx.doi.org/10.1021/la9038107. PMid:19921831.

33. Péres, L. O., Errien, N., Faulques, E., Athalin, H., Lefrant, S., Massuyeau, F., Wéry, J., Froyer, G., \& Wang, S. H. (2007). Synthesis and characterization of a new alternating copolymer containing quaterphenyl and fluorenyl groups. Polymer, 48(1), 98-104. http://dx.doi.org/10.1016/j.polymer.2006.10.038.

34. Fontana, J. P., Camilo, F. F., Bizeto, M. A., \& Faez, R. (2013). Evaluation of the role of an ionic liquid as organophilization agent into montmorillonite for NBR rubber nanocomposite production. Applied Clay Science, 83-84, 203-209. http:// dx.doi.org/10.1016/j.clay.2013.09.002.

35. Bergaya, F., Theng, B. K. G., \& Lagaly, G. (2006). Handbook of Clay Science (Vol. 1, Developments in Clay Science). Amsterdam: Elsevier.

36. Xia, C., \& Advincula, R. C. (2001). Decreased aggregation phenomena in polyfluorenes by introducing carbazole copolymer. Macromolecules, 34(17), 5854-5859. http://dx.doi.org/10.1021/ ma002036h.

37. Ranger, M., Rondeau, D., \& Leclerc, M. (1997). New WellDefined Poly(2,7-fluorene) Derivatives: Photoluminescence and Base Doping. Macromolecules, 30(25), 7686-7691. http:// dx.doi.org/10.1021/ma970920a.

38. Scherf, U., \& List, E. J. W. (2002). Semiconducting polyfluorenes: towards reliable structure: property relationships. Advanced Materials, 14(7), 477-487. http://dx.doi.org/10.1002/15214095(20020404)14:7<477::AID-ADMA477>3.0.CO;2-9.

39. Cassemiro, S. M., Thomazi, F., Roman, L. S., Marletta, A., \& Akcelrud, L. (2009). Effect of conjugation length on photophysical properties of a conjugated-non-conjugated multiblock copolymer. Synthetic Metals, 159(19-20), 19751982. http://dx.doi.org/10.1016/j.synthmet.2009.07.004.

Received: June 16, 2014

Revised: June 29, 2015 Accepted: Aug. 31, 2015 